\title{
A IMPORTÂNCIA DO ENSINO, PESQUISA E EXTENSÃO NA FORMAÇÃO DO ALUNO DO ENSINO SUPERIOR
}

\section{ARTIGO DE REVISÃO}

SILVA, Miriam Ferreira da ${ }^{1}$

MENDOZA, Cynthia Carolina González ${ }^{2}$

SILVA, Miriam Ferreira da. MENDOZA, Cynthia Carolina González. A importância do ensino, pesquisa e extensão na formação do aluno do Ensino Superior. Revista Científica Multidisciplinar Núcleo do Conhecimento. Ano 05, Ed. 06, Vol. 08, pp. 119133. Junho de 2020. ISSN: 2448-0959, Link de acesso: https://www.nucleodoconhecimento.com.br/educacao/pesquisa-e-extensao

\section{RESUMO}

O presente estudo é uma abordagem sobre importância do ensino, pesquisa e extensão na formação do aluno do ensino superior, onde objetiva analisar cada item do tripé, ramificando os objetivos específicos em 2 aspectos: 1- Esclarecer o que é ensino, pesquisa e extensão, para maior entendimento dos termos; 2 Investigar como

${ }^{1}$ Mestranda em Ciências da Educação; Pós graduanda em Educação a Distância: Elaboração de Materiais, Tutoria e Ambientes Virtuais; Graduada em Educação Física Bacharelado e graduando em Letras: Português/Inglês.

2 Doutorado em Educação, com ênfase em Gestão do Ensino Superior; Mestrado em Tecnologia da Informação e Comunicação em Educação e Treinamento; Especialização em Auditoria e Controle de Gestão; Especialização em Planejamento Estratégico Nacional; Especialização em Garantia da Qualidade: Políticas Públicas e Gestão Universidade; Especialização em Avaliação Educacional; Especialização em Educação Bilíngue; Especialização em Gestão e Administração Educacional; Especialização na área de Matemática do $3^{\circ}$ ciclo do EEB; Graduada em Direito e Bacharel em Ciências da Educação. 
o ensino, pesquisa e extensão pode ser abordado de modo a contribuir para a inclusão do aluno em seu ensino/aprendizagem. A metodologia utilizada é de abordagem qualitativa, quanto ao objetivo realizou pesquisa exploratória com levantamento bibliográfico baseado em autores conhecidos através da experiência acadêmica do curso de mestrado em Ciências da Educação, no qual a conclusão ocorre através da interpretação de livros e artigos dos mesmos.

Palavras-chave: Ensino, pesquisa, extensão, Ensino Superior.

\section{INTRODUÇÃO}

A educação superior atualmente encontra-se atrelada à globalização, novas tecnologias e fomento para formação de profissionais preparados para o mercado de trabalho, enquanto em séculos anteriores apresentavam caráter humanístico e poucos brindavam a oportunidade de ingresso em uma universidade (PRANDI, 2009). Hoje a integração ao ensino superior é acessível, pois, além da existência de universidades públicas, o Brasil possui inúmeras faculdades particulares com programas governamentais que facilitam a inclusão de pessoas de baixa renda.

Segundo Severino (2017) O ensino superior historicamente advindo da tradição ocidental, tem por objetivo 3 premissas: 1 - formação profissional dentro de diversas áreas e técnicas, resultantes do ensino/aprendizagem; 2- formação de cientistas como produto do conhecimento metodológico e de conteúdos de múltiplas especialidades de formação; 3- formação de pessoas com senso social e reiterado de sua cultura histórica e social. $O$ autor destaca que através desses objetivos a educação superior demanda em prol da sociedade. Além de fornecedora do conhecimento, a universidade comunga em prestar serviço à sociedade inserida.

As transformações no ensino de forma geral foram acontecendo de acordo com as novas necessidades de mercado e também da população, já que a universidade só é legitimada quando envolvida em atividades voltadas para os anseios da sociedade em que se encontra (DURHAM, 1989). O ensino, pesquisa e extensão forma um tripé obrigatório nas universidades e são indissociáveis através do artigo 207 da 
Constituição de 1998 (BRASIL, 1998). A tríade além de contribuir para a produção universitária, contempla o papel solidário, social e cultural para com a sociedade (MOITA e ANDRADE, 2005).

Referente à importância dos 3 elementos fundamentais para a formação superior é necessário metodologias que contribuam para um equilíbrio interativo entre os mesmos, de maneira que os alunos absorvam os benefícios da tríade. Severino (2017) Aponta que o ensino e o aprendizado resultam no conhecimento, tal conhecimento implica em uma construção do objeto, logo o objeto precisa ser investigado de maneira sistemática e metodológica, evidenciando o quão importante o papel da pesquisa. Basicamente toda ideia fundamentada através do empirismo ou experiência vivida não é o bastante para qualquer comprovação científica e sim na abordagem dos objetos através de fontes primárias. O autor aponta também que os objetos a serem pesquisados devem estar inteiramente interligados à sociedade, mantendo uma prática resultante à reflexão social, não somente com preceito técnico/científico.

Estudos de diversos autores como Cunha, (1996); Pimenta, (2002); Moita e Andrade, (2005); Esteves, (2008); Sônego, (2015); Severino, (2017) afirmam que os professores precisam estar pedagogicamente preparados, se tornando motivadores do aluno, aplicando metodologias de ensino que cumpram os requisitos curriculares e a aplicação indissociável do ensino, pesquisa e extensão de maneira transformadora contribuindo para a formação da sociedade do conhecimento.

A compreensão do tripé nem sempre se consolida, pois ao ingressar em um curso de graduação superior os alunos se deparam com diversas dificuldades, bem como a adaptação a um novo sistema de ensino, relação entre professor e aluno, grade curricular do curso pretendido entre diversos aspectos (OLIVEIRA et al., 2014). Ao sair do ensino médio alguns alunos não sabem ao menos o significado da palavra ensino, além de não assimilar o porquê de determinadas disciplinas ou metodologias ao deparar com o currículo do curso escolhido. Além dessa problemática a compreensão da pesquisa e extensão, carece de um melhor esclarecimento. 
Oliveira et al (2014) afirmam que é necessário metodologias de ensino aplicadas de forma efetiva, assumindo o professor um papel essencial no processo de adaptação do estudante. Sendo assim o presente estudo objetiva em analisar o ensino, pesquisa e extensão na formação do aluno do ensino superior no qual se ramifica 2 objetivos específicos:

1- Esclarecer o que é ensino, pesquisa e extensão, para maior entendimento dos termos.

2- Investigar como o ensino pesquisa e extensão pode ser abordado de modo a contribuir para a inclusão do aluno em seu ensino/aprendizagem.

A metodologia utilizada para a realização da pesquisa é de abordagem qualitativa para realização da análise ao tema, baseado em fundamentos de autores especialistas.

Segundo Gerhardt e Silveira (2009) a pesquisa qualitativa não objetiva em uma abordagem com representação numérica e sim em uma compreensão aprofundada do objeto a ser estudado, portanto referente ao objetivo utilizou-se a pesquisa exploratória de levantamento bibliográfico. O procedimento técnico de cunho bibliográfico orientou na formulação da conclusão, baseada nos esclarecimentos dos termos ensino, pesquisa e extensão e na investigação de como o tripé pode ser abordado pelos professores de maneira que possa incluir seus alunos conduzindo para uma melhor efetividade ao ensino/aprendizagem.

Consulta bibliográfica fundamentada em fontes como artigos científicos e livros correspondentes ao tema ensino, pesquisa e extensão, de autores familiarizados pela experiência adquirida no decorrer do curso de mestrado em Ciências da Educação.

\section{O ENSINO SUPERIOR SOBRE A FACE DO PROFESSOR}

O ensino é uma maneira de transmitir o conhecimento resultando em um aprendizado ao ensinado, essa transmissão do saber no ensino superior é contemplado de maneira enérgica onde o conhecimento é fundamentado atravessando etapas como produção, reprodução, sistematização, organização, se propagando como o 
conhecimento explícito que se expande e se universalizando (SEVERINO, 2017). Nessa linha de pensamento é notável que o aluno não é somente o espectador, mas também um atuante situado intrinsecamente em todo processo de construção do conhecimento para que se consolide o que foi absorvido.

Para que aconteça o processo de ensino de forma eficaz, a metodologia aplicada pelo docente torna-se um fator de grande complexidade, pois através do transmissor da informação, é que o receptor irá absorver e manusear o que apreendeu. Em observação a esse fato o estudo de Sônego (2015) aborda os desafios da universidade do século XXI enfatizando algumas reflexões sobre a posição do docente mediante ao processo, na ocasião é claramente observado um círculo viciante onde a cultura do docente ao seu caminho de formação, se manifesta incessantemente em seu método de ensino, sendo assim, alguns focam no ensino somente para pesquisa, outros para formação de profissionais prontos ao mercado de trabalho mas sem nenhuma perspectiva de avaliações críticas construtivas, e em ocasiões de universidades privadas o docente erroneamente passa a transmitir o ensino como relação mercadológica, retrocedendo de aluno para cliente. Tais observâncias da autora resulta na reflexão de que o professor não pode se portar como um transmissor de conteúdos e sim como mediador do conhecimento.

Para Pimenta e Anastasiou (2002 p. 188):

Os professores e a profissionalização docente estão presos em um triângulo de interesses e imposições concomitantes: 1) ser catalisadores da sociedade do conhecimento e toda a propriedade e prosperidade que promete trazer; 2) ser elementos de resistência à sociedade do conhecimento e a todos os riscos e ameaças à igualdade, à comunidade e à vida pública; 3) ser vítimas da sociedade do conhecimento em um mundo onde o aumento das expectativas em relação à educação é contrabalançado com soluções padronizadas oferecidas com um custo mínimo. 
Referindo-se ainda os autores ao comportamento dos docentes na perspectiva de catalisadores da sociedade do conhecimento, tal profissional precisa estar apto a ensinar diferente da forma que foi ensinado, atribuindo que seus alunos aprendam de forma inovadora já que com o tempo tudo vai se atualizando, e desse modo o aprendizado não é somente momentâneo e sim continuado, não permanecendo estagnado, como scripts a serem seguidos e repassados. Em reflexão ao raciocínio dos autores onde citam os professores como elementos da resistência, evidencia-se a atenção que é necessária na construção do aprendizado, englobando os aspectos sociais e emocionais de maneira didática, para que os futuros profissionais aprendam se portar perante as adversidades, comportamentos e convivências afetivas. Desfragmentando que o ensino seja somente voltado para o lado cognitivo e sim salientando e explorando toda a forma de aprendizado que tal aluno é capaz de desenvolver.

Ainda na perspectiva do ensino superior na face do professor, é de suma importância que o currículo da graduação escolhida pelo aluno seja elaborado e apresentado de forma clara, evidenciando sua notabilidade no contexto do curso. Em estudos de Esteves (2008); Felício e Possani (2013); Mesquita, Flores e Lima (2018) são realizadas análises corroborativas sobre o currículo no ensino superior, os autores abordam que todo contexto curricular se baseia e ramifica em diversos aspectos:

Social, Político, Econômico e Cultural resultando em uma visão panorâmica em que o docente necessita interligar à prática pedagógica, levando em consideração todo contexto social, refletindo sobre os aspectos intrinsecamente envolvidos como a globalização e propostas atreladas às disciplinas, mantendo uma organização metodológica de ensino, capaz de superar as adversidades encontradas no trajeto do aluno como também na relação professor-aluno, aluno-instituição e alunoaprendizado.

Em observação ao nível de globalização da atualidade, as instituições estão cada vez mais capacitadas ao desenvolvimento de tecnologias inovadoras com processos de inovações condizentes ao que o mercado necessita, exigindo mais dos profissionais que fazem parte da produção do conhecimento. No entanto é necessário a atenção 
para que não seja desvirtuado do papel do docente a essência principal que envolve o processo do ensino-aprendizagem (SILVA, 2015).

\section{A UTILIZAÇÃO DA PESQUISA COMO MÉTODO DE ENSINO}

A pesquisa em nível de graduação superior funda uma nova forma de aprendizado, focalizando o conhecimento através de metodologias que nos farão conhecer um objeto de estudo, ou seja, Severino (2017, p.20) afirma que "o conhecimento se dá como construção do objeto que se conhece(...)" onde "(...)a atividade de ensinar e aprender está intimamente vinculada a esse processo de construção de conhecimento(...)". Para o autor, o conhecimento através da construção do objeto resulta em uma inquirição da pesquisa como base do aprendizado, logo só se pode aprender pesquisando.

Conhecimento torna-se científico e não o conhecimento popular como dantes. O Conhecimento popular por sua vez desprende-se do empirismo vivido no cotidiano, resultando em um processo sistemático abrangendo a formulação de hipóteses sobre o objeto, submetendo-o a uma investigação planejada e interpretada com auxílio de teorias e metodologias (MARCONI e LAKATOS, 2003).

Para Severino $(2008,2017,2018)$ tal conhecimento acontece através de práticas teóricas (leitura e consultas documentais, bibliográficas, literárias) e acesso a pesquisas empíricas (constatação do conhecimento através da experiência), incluídas na estratégia do docente, transportando entendimento e despertando no aluno a aceitação do desconhecido, envolvendo os alunos que saíram do ensino médio na interatividade no campo da pesquisa. Tal inclusão requer um sistema organizacional planejado tanto do professor quanto do aluno. Severino (2008) aborda como o docente precisa direcionar o aluno importando as necessidades do currículo e as particularidades das disciplinas apresentadas. Na mesma obra ressalta que não somente uma disciplina isolada siga as perspectivas de metodologia do ensino à pesquisa, mas sim todos os docentes das diversas matérias incluídas no programa da graduação, interagindo de maneira sistematizada com o intuito do desenvolvimento 
de um aluno pesquisador, buscando fontes científicas e seguras que complementam o conteúdo abordado em sala de aula.

Em consonância ao fato do planejamento por parte do docente, Severino (2008) concede um modelo de programação, destacando alguns tópicos de maneira organizada, evidenciando ao aluno o porquê de aprender, o que aprender e como aprender tal disciplina com a estratégia da pesquisa. Confira abaixo:

\section{Quadro 1: Planejamento do Docente}

Justificativa - Nesse momento o professor atribui a importância da disciplina ao aluno, de maneira que o aluno compreenda a razão de aprender o conteúdo.

Objetivos - Ampliar a visão do aluno de como a disciplina corresponderá para um resultado final em atribuição à graduação do aluno, ou seja, um ponto de chegada.

Conteúdos Temáticos - Nesse tópico a sensatez do professor é crucial, pois a partir de agora o aluno aprenderá como abordar os temas da disciplina ao consenso real de maneira a agregar informações dentro de uma delimitação com o que de fato é relevante para seu aprendizado.

Metodologia do Trabalho - De forma clara apresentar ao aluno as variadas maneiras de como irão trabalhar com seus conteúdos temáticos no decorrer do curso.

Avaliação - Com clareza apresentar ao aluno a forma que avaliará suas diversas atividades, de maneira que os mesmos se sintam motivados a conquistar 0 mérito atribuído através de seus esforços.

Leituras recomendadas - Umas das mais importantes maneiras de motivar o aluno a tomar gosto pela leitura e a conhecer melhor o que está estudando, de onde seu professor está fundamentando sua linha de ensino.

Cronograma - Ao apresentar o cronograma o aluno saberá a organização de seu professor e sentirá preparado para enfrentar o que virá, uma forma também do docente evidenciar a importância de seguir o que é planejado e organizado.

Fonte: Adaptado de Severino ${ }^{15}$ 
Apresentando o planejamento acima, o conteúdo remete ao aluno tudo que irá acontecer no decorrer de determinada disciplina, submetendo-os assim os a termos que futuramente serão evidenciados no trabalho de conclusão de curso (TCC), pois todas as temáticas incluídas na programação serão apresentadas na metodologia da pesquisa, já que alguns tópicos foram apresentados no próprio planejamento do professor, trazendo assim certa familiaridade. Mesmo que pareça pouco, incluir progressivamente alguns conceitos utilizados em um TCC pode ser uma alternativa para a inclusão do aluno a termos jamais explanados no decorrer do ensino médio e fundamental.

A disciplina Metodologia Científica, aprofundará os conhecimentos voltados para a pesquisa e realização do trabalho a ser apresentado no final do curso. O enfoque da disciplina é a elaboração da produção científica ou trabalho científico através de métodos e técnicas, de forma sistemática, originando a um resultado de cunho científico, na resolução de um problema investigado (PRODANOV e ERNANI, 2009). Por esse motivo a presença do professor orientador será um grande motivador da experiência do educando.

Severino (2017) em sua obra Metodologia do Trabalho Científico aponta diversas didáticas condizentes ao amadurecimento progressivo do aluno na trajetória do curso, inclusive justifica o Programa Institucional de Bolsas de Iniciação Científica (PIBIC) ${ }^{[3]}$, - TCC e incontáveis atividades utilizadas como estratégia de potencializar o aprendizado dos discentes. O acontecimento da práxis é evidenciado através das atitudes e decisões traçando novas linhas de pensamento, senso crítico e interação social. Vale salientar que o presente estudo não aprofundou nas políticas de ensino e muito menos na deriva epistemológica, salientando no estudo a importância da pesquisa quanto à iniciação científica com o intuito de uma adaptação e inclusão do aluno nas práticas acadêmicas.

\section{EXTENSÃO UNIVERSITÁRIA E A INCLUSÃO DA SOCIEDADE}

Um dos objetivos e dever das universidades, é a capacidade de atender o que a sociedade anseia, de maneira a satisfazer às suas necessidades, problemas, atribuir 
melhorias, entre diversos benefícios. Referente à inter-relação entre sociedade/universidade Durham (1989) aborda a "relativa independência da universidade", afirmação que fortalece a teoria de que factualmente a universidade goza de sua autonomia para a prestação de serviços e propostas de ensino de maneira independente, porém não goza da exclusividade em elaboração de projetos que colaboram somente em prol dos seus interesses, logo percebe-se que tais atividades são obrigatoriamente legitimadas à inclusão da sociedade, onde a mesma está interligada e beneficiada através dos serviços prestados pela instituição. O autor ainda atribui essa afirmativa quando justifica que até mesmo o material e metodologia a serem utilizados na instituição, precisam estar associados ao contexto atual político e cultural, condizentes à sociedade. A obra aponta a finalidade da construção universitária como transportadora do conhecimento universal e independente em relação à igreja e interesses políticos da época medieval, para tanto sempre com o objetivo da inclusão da sociedade até hoje na época moderna.

Martins em seu estudo de Ensino-Pesquisa-Extensão como fundamento metodológico da construção do conhecimento na universidade sintetiza o histórico da extensão universitária no Brasil, evidenciando sua inclusão na época da ditadura, o intuito era atribuir à população de classe social carente a inclusão ao conhecimento, "políticas de desenvolvimento econômico e cultural" em parcerias internacionais, porém, elucida que a maior intenção era moldar a classe pobre para obtenção do controle social, e não por obra humanitária. Momento histórico em que o interesse na extensão universitária era manter uma classe dominante sobre a classe dominada. Após a fase citada nas décadas de 70 e 80, o trabalho de extensão nas universidades se intensifica no Brasil para um suporte atrativo e condizente ao conhecimento científico, já que através das ações e vivências são evidenciados os dados empíricos complementando as necessidades do ensino e pesquisa.

Severino (2017, p.25) enfatiza que:

A extensão se torna exigência intrínseca do ensino superior em decorrência dos compromissos do conhecimento e da educação com a sociedade, uma vez que tais processos só se legitimam, inclusive 
adquirindo sua chancela ética, se expressarem envolvimento com os interesses objetivos da população como um todo.

Referente à afirmação do autor, evidencia que os profissionais do ensino transmitem a seus alunos uma nova consciência social, que retrata um compromisso político com a sociedade. Desse modo a importância da extensão se torna como coração das pesquisas a serem realizadas, pois assim os temas evidenciados são relevantes às necessidades da população, o que reflete em resoluções de problemas existentes naquela sociedade.

A inclusão dos alunos em trabalhos de extensão se inicia através da prática em campo, com a saída da sala de aula e laboratório para o encontro físico com a população, à guisa que a obtenção do conhecimento se desenvolva através da prática. Santos e Passaglio (2016) demonstram que através da extensão o aluno se envolve em situações onde o conhecimento de forma passiva migra para uma forma ativa, no qual o mesmo, através dessa interatividade desenvolve distintas habilidades como: "Estímulo à reflexão entre teoria e prática, conhecimento do campo profissional, desenvolvimento de uma postura ética e crítica, troca $x$ transmissão do conhecimento". Isto posto a extensão universitária resulta em uma ampliação do ensino intrínseco convertido em ação extrínseca, o aluno de absorvedor também um transportador do saber.

Além da extensão promover a integração do saber teórico para o saber da prática, em razão dos trabalhos sociais, Nunes e Silva (2011); Rays (2012); Santos e Passaglio (2016), a extensão universitária também prepara o aluno para a vida profissional, já que a experiência adquirida contribui para as adversidades que serão encontradas no setor laboral.

\section{CONSIDERAÇÕES FINAIS}

O estudo apresentado objetivou em destacar a importância dos termos ensino, pesquisa e extensão, para melhor entendimento dos alunos ao ingressar em uma universidade como também agregar aos professores uma consciência de como incluir 
os discentes em atividades eficazes no ensino/aprendizagem para os futuros profissionais.

A tríade inseparável salienta que um complementa o outro já que o ensino na educação superior envolve o conhecimento do objeto através de fontes primárias no qual são fontes pesquisadas através de metodologias científicas resultando em pesquisas, ao mesmo tempo tais pesquisas precisam ser fundadas através de problemas sociais engendrado naquela sociedade e através dessas pesquisas nascem os trabalhos de extensão.

O ensino superior com o propósito profissionalizante está obsoleto já que a finalidade da universidade é formar pessoas solidárias e capazes de resolver e envolver-se nas necessidades da sociedade em que vive, não abstendo de sua cultura e munido com uma noção social.

Além da compreensão desfragmentada, onde a formação do aluno se contempla com a aquisição de uma visão ampla sabendo lidar com problemas futuros na área de atuação como também ser engajado com o trabalho em equipe e relações atitudinais que agregam crescimento em qualquer campo de atuação.

Para que a eficácia do ensino aprendizagem seja real Severino (2017) elucida que para os alunos absorverem as dinâmicas propostas pelo ensino, pesquisa e extensão é necessário que mesmo nas atividades diárias, seus professores induzam o hábito de pesquisa, porque assim o aluno vai se familiarizando com as novas formas de estudo.

Severino (2017) ainda adverte que a universidade precisa se ater aos problemas sociais já que sem isso as pesquisas realizadas não teriam o menor sentido ou importância. Para a realização das atividades é indispensável docentes capacitados com métodos pedagógicos atualizados e desvinculados de suas formações anteriores, estando sempre em desenvolvimento.

A participação dos alunos nas atividades destacadas na tríade, contribui para a sociedade do conhecimento, pessoas com visão humanística e tecnicamente 
atualizadas, mas para que isso seja efetivo, os mesmos precisam ser ensinados por professores não alienados que prezam ser os detentores do saber e sim sejam os mediadores da informação de maneira a transformar tais informações em conhecimento. Assim a sociedade do conhecimento se ampliará em uma formação continuada, contribuindo tanto para o bem social quanto para o campo profissional.

\section{REFERÊNCIAS}

BRASIL. Constituição da República Federativa do Brasil de 1988. Brasília, 5 out 1988. Acesso em: 06 de Julho de 2019. Disponível em: <http://www.planalto.gov.br/ccivil_03/constituicao/constituicao.htm $\geq$.

CUNHA, Maria Isabel. Ensino com pesquisa: a prática do professor universitário. Cad. Pesq.,São Paulo, n.97, p.31-46, maio 1996. Acesso em: 13 de Julho de 2019 Disponível em: <http://publicacoes.fcc.org.br/ojs/index.php/cp/article/view/802/813>

DURHAN, Eunice Ribeiro. A autonomia universitária: o princípio constitucional e suas implicações. NUPES e Departamento de Antropologia - FFLCH, Universidade de São Paulo 1989. Acesso em 27 de julho de 2019. Disponível em: <http://nupps.usp.br/downloads/docs/dt8909.pdf>

ESTEVES, Manuela. (2008). Para a excelência pedagógica do ensino superior. Sísifo: Revista de Ciências da Educação, ISSN 1649-4990, №. 7, 2008 (Exemplar dedicado a: Educação, Trabalho e Identidades Profissionais). p. 101-110. Disponível em: $<$ https://www.researchgate.net/publication/28240672_Para_a_excelencia_pedagogic a_do_ensino_superior $\geq$. Acesso em: 13 de julho de 19

FELÍCIO, Helena Maria Santos; POSSANI, Lourdes Fátima Paschoaleto. Análise crítica de currículo: um olhar sobre a prática pedagógica. Currículo sem Fronteiras, v. 13, n. 1, p. 129-142, 2013. Acesso em: 13 de Julho de 2019 Disponível em: <http://www.curriculosemfronteiras.org/vol13iss1articles/felicio-possani.pdf .

GERHARDT, Tatiana Engel; SILVEIRA, Denise Tolfo. Métodos de pesquisa UAB/UFRGS e pelo Curso de Graduação Tecnológica - Planejamento e Gestão para 
o Desenvolvimento Rural da SEAD/UFRGS. - Porto Alegre: Editora da UFRGS, 2009. Acesso em: 24/08/2019 Disponível em: $<$ http://www.ufrgs.br/cursopgdr/downloadsSerie/derad005.pdf>

GERHARDT, Tatiana Engel; SILVEIRA, Denise Tolfo (organizadoras). Métodos de Pesquisa. 1a Ed. Porto Alegre: Editora da UFRGS, 2009. Disponível em: <http://www.ufrgs.br/cursopgdr/downloadsSerie/derad005.pdf>. Acesso em: 09 de Agosto. 2019.

MARCONI, Marina Andrade; LAKATOS, Eva Maria. Fundamentos de metodologia científica. 5. ed. São Paulo: Atlas, 2003.

MARTINS, L. M. Ensino-Pesquisa-Extensão como fundamento metodológico da construção do conhecimento na universidade. UNESP - São Paulo. Acesso em: 29 de Julho de 2019. Disponível em: <file:///C:/Users/Miriam/Downloads/Martins_Ensino_-_Pesquisa_-_Extensa7710\%20(1).pdf>

MOITA, Filomena Maria Gonçalves da Silva Cordeiro; ANDRADE, Fernando Cézar. A indissociabilidade entre ensino, pesquisa e extensão: o caso do estágio de docência na pós-graduação. Olhar de Professor, Ponta Grossa v. 8, n. 2, p. 77-92 Jul./Dez. Acesso em: 04 julho de 2019 Disponível

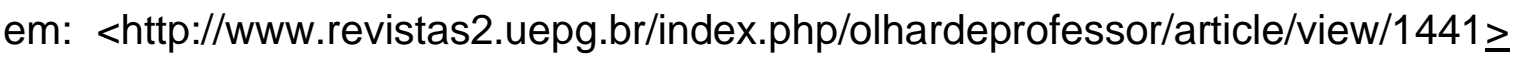

NUNES, Ana Lúcia de Paula Ferreira; SILVA, Maria Batista da Cruz. A extensão universitária no ensino superior e a sociedade. Mal-Estar e Sociedade - Ano IV - n. 7 - Barbacena - julho/dezembro 2011 - p. 119-133 Acesso em: 02 de Agosto de 2019 Disponível em: <http://revista.uemg.br/index.php/malestar/article/view/60/89>

OLIVEIRA, Clarissa Tochetto; WILES, Jamille Mateus; FIORIN, Pascale Chechi; DIAS Ana Cristina Garcia. Percepções de estudantes universitários sobre a relação professor-aluno. Psicol. Esc. Educ.[online]. 2014, vol.18, n.2, pp.239-246. ISSN 2175-3539. Acesso em:02 de agosto de 2019 Disponível em: $<$ http://dx.doi.org/10.1590/2175-3539/2014/0182739>. 
PIMENTA, Selma Garrido; ANASTASIOU, Léa das G. Camargos. Docência no Ensino Superior. Vol. 1 - Cortez Editora, 2002.

PRANDI, Luiz Roberto. Tendências do processo didático-pedagógico no Ensino Superior na contemporaneidade. Akrópolis Umuarama, v. 17, n. 3, p. 137-142, jul./set. 2009.

PRODANOV, Cleber Cristiano; FREITAS, Ernani Cesar de. Metodologia do Trabalho Científico: métodos e técnicas da pesquisa e do trabalho acadêmico. Novo Hamburgo: Feevale, 2009. Acesso em: 25 de Julho de 2019 Disponível em: <http://www.feevale.br/Comum/midias/8807f05a-14d0-4d5b-b1ad-1538f3aef538/Ebook\%20Metodologia\%20do\%20Trabalho\%20Cientifico.pdf>

RAYS, Oswaldo Alonso. Ensino-Pesquisa-Extensão: notas para pensar a indissociabilidade. Revista Educação Especial, Santa Maria, p. 71-85, mar. 2012. ISSN 1984-686X. Disponível em: <https://periodicos.ufsm.br/educacaoespecial/article/view/5034>. Acesso em: 01 ago. 2019.

SANTOS, João Henrique de; ROCHA, Bianca Ferreira; PASSAGLIO, Kátia Tomagini. Extensão universitária e formação no ensino superior. Revista Brasileira De Extensão Universitária, v. 7, n. 1, p. 23-28, 28 maio 2016. Acesso em: 02 de Agosto de 2019

<https://periodicos.uffs.edu.br/index.php/RBEU/article/view/3087>

SEVERINO, Antônio Joaquim. Ensino e pesquisa na docência universitária: caminhos para a integração. 3 Universidade de São Paulo Faculdade de Educação FEUSP Cadernos de Pedagogia Universitária n.3 p.1-40 2008. Disponível em: <http://www.prpg.usp.br/attachments/article/640/Caderno_3_PAE.pdf> Acesso em: 17 de julho de 2019.

SEVERINO, Antônio Joaquim. Metodologia do Trabalho Científico. São Paulo: Cortez. (2017) 
SEVERINO, Antônio Joaquim. Docência universitária: a pesquisa como princípio pedagógico. Revista @mbienteeducação, [S.I.], v. 2, n. 1, p. 120 - 128, mar. 2018. ISSN 1982-8632. Disponível em: <http://publicacoes.unicid.edu.br/index.php/ambienteeducacao/article/view/540>. Acesso em: 20 jul. 2019.

SILVA Glaucia Maria, RIVAS Noelí Prestes Padilha, MARQUES Maria Auxiliadora de Rezende, CONTE Karina de Melo. A pós-graduação como lócus da formação docente para o ensino superior: diálogos entre didática e currículo. Rev Port Pedagog. 2015; 49(2):55-74 Disponível em: https://impactumjournals.uc.pt/rppedagogia/article/view/2741/1919 Acesso em: 13 de julho de 2019

SÔNEGO, Aline. Os desafios da universidade no século XXI e algumas reflexões sobre a posição docente frente a este processo. Revista Brasileira de Ensino Superior, Passo Fundo, v. 1, n. 1, p. 30-35, jun. 2015. ISSN 2447-3944. Acesso em: 09 julho de 2019.2 Disponível em: https://seer.imed.edu.br/index.php/REBES/article/view/822.

\section{APÊNDICE - REFERÊNCIA DE NOTA DE RODAPÉ}

3. Programa do CNPq que concede anualmente bolsas de Iniciação Científica https://www.prp.unicamp.br/pt-br/pibic-0

Enviado: Janeiro, 2020.

Aprovado: Junho, 2020. 